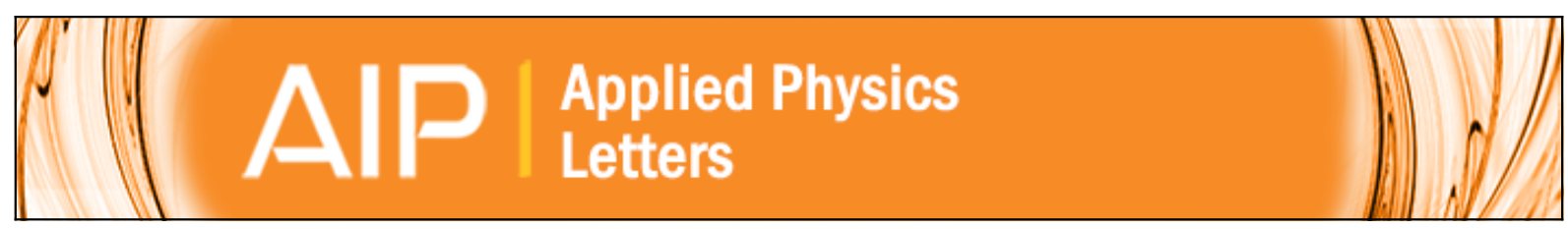

\title{
Band gap engineering of In2O3 by alloying with T12O3
}

David O. Scanlon, Anna Regoutz, Russell G. Egdell, David J. Morgan, and Graeme W. Watson

Citation: Applied Physics Letters 103, 262108 (2013); doi: 10.1063/1.4860986

View online: http://dx.doi.org/10.1063/1.4860986

View Table of Contents: http://scitation.aip.org/content/aip/journal/apl/103/26?ver=pdfcov

Published by the AIP Publishing

$\stackrel{A}{A} \mathbb{P} P$ Re-register for Table of Content Alerts

Create a profile.

Sign up today! 


\title{
Band gap engineering of $\operatorname{In}_{2} \mathrm{O}_{3}$ by alloying with $\mathrm{Tl}_{2} \mathrm{O}_{3}$
}

\author{
David O. Scanlon, ${ }^{1,2, a)}$ Anna Regoutz, ${ }^{3}$ Russell G. Egdell, ${ }^{3}$ David J. Morgan, ${ }^{4}$ \\ and Graeme W. Watson ${ }^{5}$ \\ ${ }^{1}$ Kathleen Lonsdale Materials Chemistry, Department of Chemistry, University College London, \\ 20 Gordon Street, London WC1H OAJ, United Kingdom \\ ${ }^{2}$ Diamond Light Source Ltd., Diamond House, Harwell Science and Innovation Campus, Didcot, \\ Oxfordshire OXI1 ODE, United Kingdom \\ ${ }^{3}$ Department of Chemistry, Inorganic Chemistry Laboratory, University of Oxford, South Parks Road, \\ Oxford OX1 3QR, United Kingdom \\ ${ }^{4}$ Cardiff Catalysis Institute (CCI), School of Chemistry, Cardiff University, Park Place, Cardiff CF10 3AT, \\ United Kingdom \\ ${ }^{5}$ School of Chemistry and CRANN, Trinity College Dublin, Dublin 2, Ireland
}

(Received 19 September 2013; accepted 16 December 2013; published online 30 December 2013)

\begin{abstract}
Efficient modulation of the bandgap of $\mathrm{In}_{2} \mathrm{O}_{3}$ will open up a route to improved electronic properties. We demonstrate using ab initio calculations that $\mathrm{Tl}$ incorporation into $\mathrm{In}_{2} \mathrm{O}_{3}$ reduces the band gap and confirm that narrowing of the gap is observed by X-ray photoemission spectroscopy on ceramic surfaces. Incorporation of $\mathrm{Tl}$ does not break the symmetry of the allowed optical transitions, meaning that the doped thin films should retain optical transparency in the visible region, in combination with a lowering of the conduction band effective mass. We propose that Tl-doping may be an efficient way to increase the dopability and carrier mobility of $\mathrm{In}_{2} \mathrm{O}_{3}$. (C) 2013 AIP Publishing LLC. [http://dx.doi.org/10.1063/1.4860986]
\end{abstract}

Transparent conducting oxides (TCOs) are now ubiquitous in modern optoelectronic devices, having applications in solar cells, flat panel displays, smart windows, etc. ${ }^{1}$ Sn-doped $\mathrm{In}_{2} \mathrm{O}_{3}\left(\mathrm{In}_{2} \mathrm{O}_{3}: \mathrm{Sn}\right.$ or ITO), which has an optical band gap of $\sim 3.75 \mathrm{eV}$, is currently the industry standard $n$-type TCO, possessing concomitant carrier concentrations exceeding $10^{21} \mathrm{~cm}^{-3}$, resistivities below $10^{-5} \Omega \mathrm{cm}$, and transparency as high as $90 \% .^{2}$ Over the past decade concerns over the availability and abundance of In have resulted in large fluctuations in the cost of In and have spawned a research drive to replace In in TCOs. ${ }^{3}$ Alternative TCOs, namely, $\mathrm{SnO}_{2}: \mathrm{F}$ (FTO), $\mathrm{SnO}_{2}: \mathrm{Sb}$ (ATO), and $\mathrm{ZnO}: \mathrm{Al}$ (AZO) have all received much attention. However, they have thus far failed to equal the consistent high performance of ITO. Recently, a new perovskite $\mathrm{TCO}, \mathrm{BaSnO}_{3}$, has emerged as a more earth abundant alternative although investigations into this material are only in their infancy. ${ }^{4}$

The excellent dopability and high performance of $\operatorname{In}_{2} \mathrm{O}_{3}$ as an $n$-type TCO can be easily understood from an examination of its band structure and its band alignment relative to other TCOs. An ideal $n$-type TCO materials should possess (i) a large optical band gap ensuring that the material is transparent, (ii) the ability to become a degenerate semiconductor when donor doped, (iii) a large separation between the conduction band minimum $(\mathrm{CBM})$ and the next lowest conduction band $(\mathrm{CBM}+1)$ ensuring that when donor doped, the system can still remain transparent, and (iv) a small effective mass at the CBM, ensuring good electron mobility. Point (ii) is generally dominated by the position of the CBM relative to the vacuum level, with the greater the distance of the CBM from the vacuum level indicating a greater electron affinity (EA), and thus greater $n$-type dopability. ${ }^{5}$

\footnotetext{
a)Email: d.scanlon@ucl.ac.uk
}

Until 2008, the fundamental band alignment of $\mathrm{In}_{2} \mathrm{O}_{3}$ had not been well understood, due to confusion over the exact nature of the fundamental band gap. Walsh et al. used a combination of $a b$ initio calculations and photoelectron spectroscopy measurements to show that the fundamental band gap of $\mathrm{In}_{2} \mathrm{O}_{3}$ was not indirect in nature as had been proposed previously. ${ }^{6}$ The fundamental band gap is $\sim 0.8 \mathrm{eV}$ smaller than the optical band gap of $\mathrm{In}_{2} \mathrm{O}_{3}$, as transitions from states within $0.8 \mathrm{eV}$ of the valence band maximum (VBM) to the conduction band (CB) are symmetry disallowed. ${ }^{6,7}$ This understanding helped to rationalize previous XPS band alignments, which had considered that the CBM of $\mathrm{In}_{2} \mathrm{O}_{3}$ was $3.75 \mathrm{eV}$ above the VBM. The ability to lower the $\mathrm{CBM}$ of $\mathrm{In}_{2} \mathrm{O}_{3}$ relative to the vacuum level and also to simultaneously decrease the effective mass of the CBM would have a huge effect on its electronic conductivity and also on the ability to modulate the workfunction and open up the material for other applications, such as hole injection layers in organic photovoltaics.

Band gap engineering of semiconductors may be approached in a number of ways, including strain engineering, ${ }^{8}$ inducing lattice disorder, ${ }^{9}$ or chemical doping. ${ }^{10}$ To date, however, no reports of the modulation of the band gap of $\mathrm{In}_{2} \mathrm{O}_{3}$ exceeding $\sim 0.1 \mathrm{eV}$ have been reported. In this Letter we propose Tl-doping as an efficient mechanism for lowering the band gap of $\operatorname{In}_{2} \mathrm{O}_{3}$. We demonstrate using density functional theory (DFT) and that the fundamental band gap of $\mathrm{In}_{2-\mathrm{x}} \mathrm{Tl}_{\mathrm{x}} \mathrm{O}_{3} \quad(0<\mathrm{x}<0.125)$ can be tuned from $\sim 2.75 \mathrm{eV}$ to $2.25 \mathrm{eV}$. Crucially, the nature of optical transitions are not altered in the doped system, meaning that the optical band gap can be modulated from $\sim 3.75 \mathrm{eV}$ to $\sim 3.25 \mathrm{eV}$, maintaining optical transparency for the doped system. High resolution X-ray photoemission measurements provide provisional evidence of narrowing of the fundamental gap at Tl-rich ceramic surfaces of $\operatorname{In}_{1.98} \mathrm{Tl}_{0.02} \mathrm{O}_{3}$. 
All our DFT calculations were performed using the VASP code, ${ }^{11}$ with interactions between the cores (In:[Kr], $\mathrm{Tl}:[\mathrm{Xe}]$, and $\mathrm{O}:[\mathrm{He}])$ and the valence electrons described using the Projector Augmented Wave method. ${ }^{12}$ The calculations were performed using the HSE06 hybrid functional as proposed by Krukau et al. ${ }^{13}$ In the HSE06 approach, a value of exact nonlocal exchange, $\alpha$, of $25 \%$, and screening parameter of $\omega=0.11 \mathrm{bohr}^{-1}$ are added to the Perdew Burke Ernzerhof (PBE) formalism. The Heyd Scuseria Ernzerhof (HSE) approach has been proven to result in structural and band gap data in better agreement with experiment than standard DFT functionals ${ }^{14}$ and, crucially, to provide an excellent description of the electronic structure of both $\mathrm{Tl}_{2} \mathrm{O}_{3}$ (Ref. 15) and $\operatorname{In}_{2} \mathrm{O}_{3}{ }^{16}$ A planewave cutoff of $400 \mathrm{eV}$ and a $k$-point sampling of Gamma-centered $3 \times 3 \times 3$ for the 40 atom primitive cell of $\mathrm{Tl}_{2} \mathrm{O}_{3}$ and $\mathrm{In}_{2} \mathrm{O}_{3}$ were used, with the structure deemed to be converged when the forces on all the atoms were less than $0.01 \mathrm{eV} \AA^{-1}$. The optical transition matrix elements and the optical absorption spectrum were calculated within the transversal approximation. ${ }^{17}$ Within this methodology, the adsorption spectra is summed over all direct VB to CB transitions and therefore ignores indirect and intraband adsorptions. ${ }^{18}$

For comparison with the DFT calculations ceramic sample of $\mathrm{In}_{1.98} \mathrm{Tl}_{0.02} \mathrm{O}_{3}$ and $\mathrm{In}_{1.88} \mathrm{Tl}_{0.12} \mathrm{O}_{3}$ were prepared by firing mixtures of $\mathrm{In}_{2} \mathrm{O}_{3}$ and $\mathrm{Tl}_{2} \mathrm{O}_{3}$ intimately ground in an agate mortar and pestle and pressed into $13 \mathrm{~mm}$ diameter pellets under a loading of 5 tonnes. The pellets were enclosed in a blanket of unpressed powder of the same composition to prevent loss of volatile $\mathrm{Tl}_{2} \mathrm{O}_{3}$ and sintered at a temperature of $600{ }^{\circ} \mathrm{C}$ for $24 \mathrm{~h}$ in recrystallised alumina crucibles. Owing to the toxicity of $\mathrm{Tl}$ and its compounds, the furnace used in this procedure was housed in a fume hood. X-ray photoelectron spectra were measured in a Kratos Axis Ultra delay line detector system using a fixed anode monochromatic Al $K \alpha$ $\mathrm{X}$-ray source operating at $120 \mathrm{~W}$ and $125 \mathrm{~mm}$ mean radius spherical sector analyser. Data were collected with a pass energy of $40 \mathrm{eV}$ for the high resolution scans. The nominal energy resolution was around $0.50 \mathrm{eV}$. The system was operated in the hybrid mode, using a combination of magnetic immersion and electrostatic lenses with spectra acquired over an area approximately $300 \times 700 \mu \mathrm{m}^{2}$. A magnetically confined charge compensation system was used to minimize charging of the sample surface, and all spectra were taken with a $90^{\circ}$ take off angle. The resulting spectra were referenced to a weak Fermi edge observed in the spectra. There was evidence of pronounced segregation of $\mathrm{Tl}$ to the near surface region of the pellets with a surface $\mathrm{Tl} /(\mathrm{In}+\mathrm{Tl})$ ratio of 0.19 (i.e., an effective $\mathrm{x}$ values of 0.38 where $\mathrm{x}$ is defined by the formula $\operatorname{In}_{2-\mathrm{x}} \mathrm{Tl}_{\mathrm{x}} \mathrm{O}_{3}$ ) as gauged by $\mathrm{Tl} 4 f$ and $\mathrm{In} 3 d$ intensities (after correction with atomic sensitivity factors supplied by the instrument manufacturer) for the sample with a nominal bulk $\mathrm{x}$ values of 0.02 . The surface $\mathrm{Tl}$ content for the sample with $x=0.12$ was 0.72 . The concentration of $\mathrm{Tl}$ in the near surface region as probed by XPS is therefore significantly greater than the bulk $\mathrm{Tl}$ levels of $\mathrm{x}=0.125$ and $\mathrm{x}=0.25$ treated in the calculations even at the very low bulk $\mathrm{x}$ values of the two samples studied in the experiments.

The stable oxides of $\mathrm{In}$ and $\mathrm{Tl}$ are the sesquioxides $(\mathrm{In} / \mathrm{Tl})_{2} \mathrm{O}_{3}$, which both crystalize in the cubic bixbyite $(\mathrm{FeMnO})$ structure, with 40 atoms (8 f.u.) in the primitive unit cell, and 80 atoms in the conventional cell. All oxygen sites in this structure are equivalent, coordinated to four cations, whereas there are two distinct cation sites $(8 b$ and $24 d$ in Wyckoff notation) which are each coordinated to 6 anions in a distorted octahedra. One quarter of all the cations occupy the $8 b$ position, with the remaining three quarters occupying the $24 d$ positions. Our calculated lattice constants for $\mathrm{In}_{2} \mathrm{O}_{3}$ and $\mathrm{Tl}_{2} \mathrm{O}_{3}$ are $10.16 \AA$ and $10.56 \AA$, which are within $0.40 \%$ and $0.02 \%$ of the experimental lattice constants respectively. The calculated band gaps at the HSE06 level are $2.75 \mathrm{eV}$ and $0.33 \mathrm{eV}$ for $\mathrm{In}_{2} \mathrm{O}_{3}$ and $\mathrm{Tl}_{2} \mathrm{O}_{3}$, respectively, in good agreement with experimental measurements.

We have tested the incorporation of one $\mathrm{Tl}$ into the 40 atom primitive cell of $\mathrm{In}_{2} \mathrm{O}_{3}$ (i.e., replacing $6.25 \%$ of the In atoms) on both the $8 \mathrm{~b}$ and $24 \mathrm{~d}$ sites. $\mathrm{Tl}$ is $0.045 \mathrm{eV}$ more stable on the $24 \mathrm{~d}$ site, indicating that it will have a small preference at room temperature for taking up this site. We have also tested whether $\mathrm{Tl}$ ions will cluster when doped into $\mathrm{In}_{2} \mathrm{O}_{3}$, by calculating different combinations of dopant ordering in an 80 atom unit cell. This analysis reveals that there is a $2 \mathrm{meV}$ preference for $\mathrm{Tl}$ ions to sit on neighbouring $24 \mathrm{~d}$ sites, meaning that there is not a large thermodynamic driving force for $\mathrm{Tl}$ clustering.

The HSE06 calculated band structures for $\mathrm{In}_{2} \mathrm{O}_{3}$, $\mathrm{In}_{1.875} \mathrm{Tl}_{0.125} \mathrm{O}_{3}, \mathrm{In}_{1.75} \mathrm{Tl}_{0.25} \mathrm{O}_{3}$, and $\mathrm{Tl}_{2} \mathrm{O}_{3}$ are shown in Figure 1. It is immediately obvious that the incorporation of $\mathrm{Tl}$ causes the band gap to decrease. This is not unexpected as the band gap of isoelectronic and isostructural $\mathrm{Tl}_{2} \mathrm{O}_{3}$ is only $0.35 \mathrm{eV}$, due to in large part to very pronounced relativistic stabilisation of the $\mathrm{Tl} 6 s$ states. ${ }^{19}$ The CBM effective masses for $\mathrm{In}_{2} \mathrm{O}_{3}, \mathrm{In}_{1.875} \mathrm{Tl}_{0.125} \mathrm{O}_{3}, \mathrm{In}_{1.75} \mathrm{Tl}_{0.25} \mathrm{O}_{3}$, and $\mathrm{Tl}_{2} \mathrm{O}_{3}$ were calculated to be $0.30,0.29,0.27$, and $0.22 m_{e}$, respectively, indicating that the inclusion of $\mathrm{Tl}$ also lowers the effective mass, and should promote higher electron mobility.

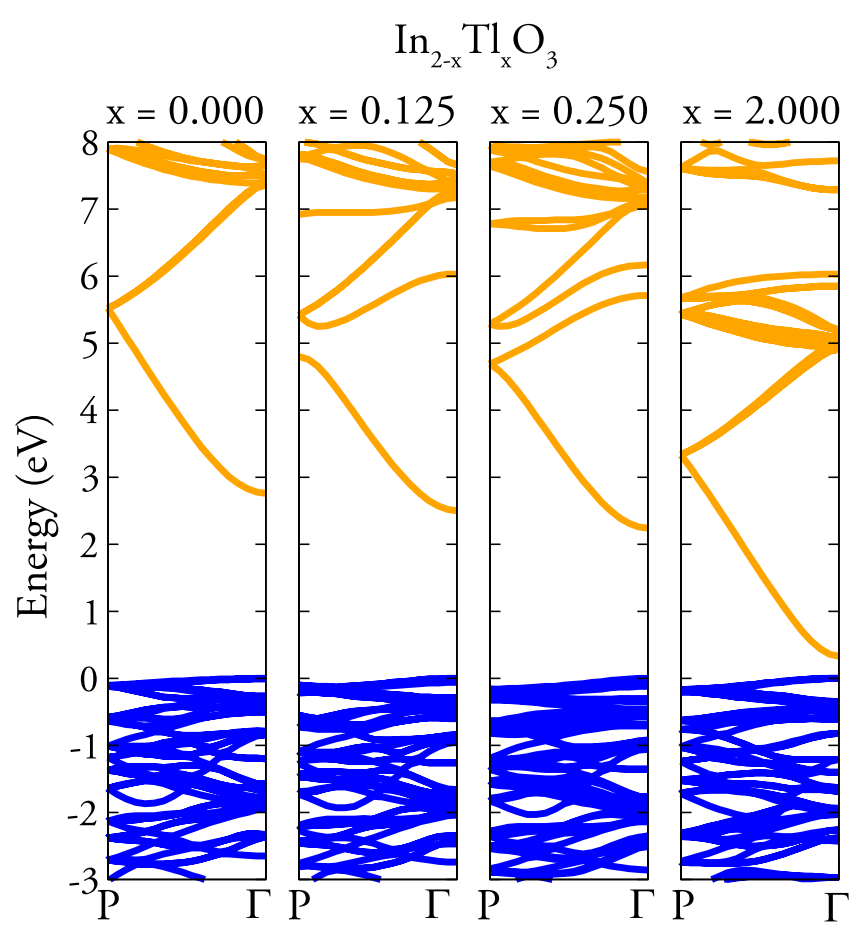

FIG. 1. Band structure of $\mathrm{In}_{2-\mathrm{x}} \mathrm{Tl}_{\mathrm{x}} \mathrm{O}_{3}$ for $\mathrm{x}=0.000,0.125,0.250$, and 2.000. Blue and orange denote valence bands and conduction bands. The VBM is set to $0 \mathrm{eV}$ in each case. 
A simple band alignment derived from a charge neutrality level (CNL, or branch point energy) approach ${ }^{20}$ is displayed in Figure 2. This approximate model places the ionization potential of $\mathrm{In}_{2} \mathrm{O}_{3}$ at $7.81 \mathrm{eV}$, which is in good agreement with recent calculated ${ }^{21}$ and experimental measurements. ${ }^{22} \mathrm{It}$ is clear that the incorporation of $\mathrm{Tl}$ lowers the position of the CBM relative to the vacuum level, necessarily increasing the distance that the $\mathrm{CNL}$ is above the CBM. This result indicates that Tl-doped $\operatorname{In}_{2} \mathrm{O}_{3}$ should be easier to dope $n$-type and opens up the possibility that oxygen vacancies, which are the dominant intrinsic defect in $\mathrm{In}_{2} \mathrm{O}_{3}$ and $\mathrm{Tl}_{2} \mathrm{O}_{3}$, might transition from being relatively deep donors in bulk $\mathrm{In}_{2} \mathrm{O}_{3}$ (Ref. 23) towards being fully ionized as they are in $\mathrm{Tl}_{2} \mathrm{O}_{3} .{ }^{15}$

As we have now established that $\mathrm{Tl}$ incorporation decreases the fundamental band gap of $\operatorname{In}_{2} \mathrm{O}_{3}$, it is instructive to investigate how $\mathrm{Tl}$ incorporation affects the optical band gap. Both $\operatorname{In}_{2} \mathrm{O}_{3}$ and $\mathrm{Tl}_{2} \mathrm{O}_{3}$ possess symmetry disallowed transitions from states within $\sim 0.8 \mathrm{eV}$ and $\sim 1.2 \mathrm{eV}$, respectively, of the VBM to the CBM, meaning that their optical band gap is considerably larger than their fundamental band gap. The HSE06 calculated optical absorption spectra for $\mathrm{In}_{2} \mathrm{O}_{3}, \mathrm{In}_{1.875} \mathrm{Tl}_{0.125} \mathrm{O}_{3}$, and $\mathrm{In}_{1.75} \mathrm{Tl}_{0.25} \mathrm{O}_{3}$ are displayed in Figure 3. Tl-doping up to $12.5 \%$ does not affect allowed transitions from $\mathrm{VB}$ to $\mathrm{CB}$, meaning that even with a reduced fundamental band gap, the optical band gap remains larger than the threshold for optical transparency of $3.1 \mathrm{eV}$. This indicates that although the CBM has been lowered, increasing the n-type dopability, the doped material is still a TCO.

Very provisional experimental verification of these ideas is provided by the valence band $\mathrm{X}$-ray photoemission spectra shown in Figure 4. For nominally undoped $\operatorname{In}_{2} \mathrm{O}_{3}$ the onset of the valence band edge is about $2.88 \mathrm{eV}$ below the surface Fermi level, as has been found previously. ${ }^{6,24}$ The position of the valence band edge is influenced by a number of factors including experimental spectral broadening ${ }^{25}$ and band bending at the surface, leading for undoped $\mathrm{In}_{2} \mathrm{O}_{3}$ to formation of

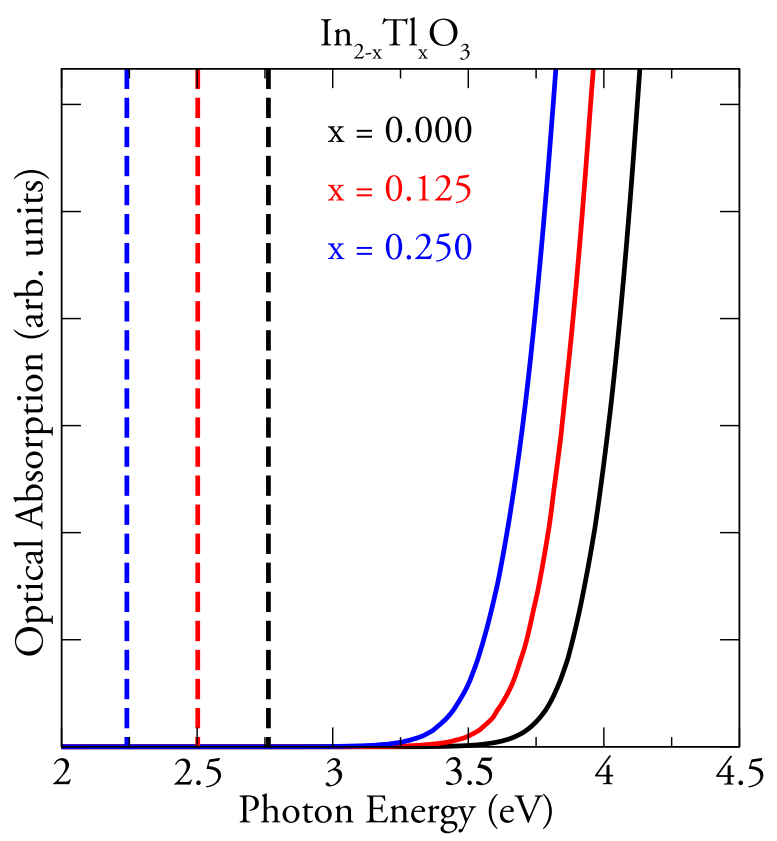

FIG. 2. HSE06 calculated optical absorption spectra for $\mathrm{In}_{2-\mathrm{x}} \mathrm{Tl}_{\mathrm{x}} \mathrm{O}_{3}$ for $\mathrm{x}=0.000,0.125$, and 0.250 . Dashed lines indicate fundamental band gap, and full lines indicate optical absorption.

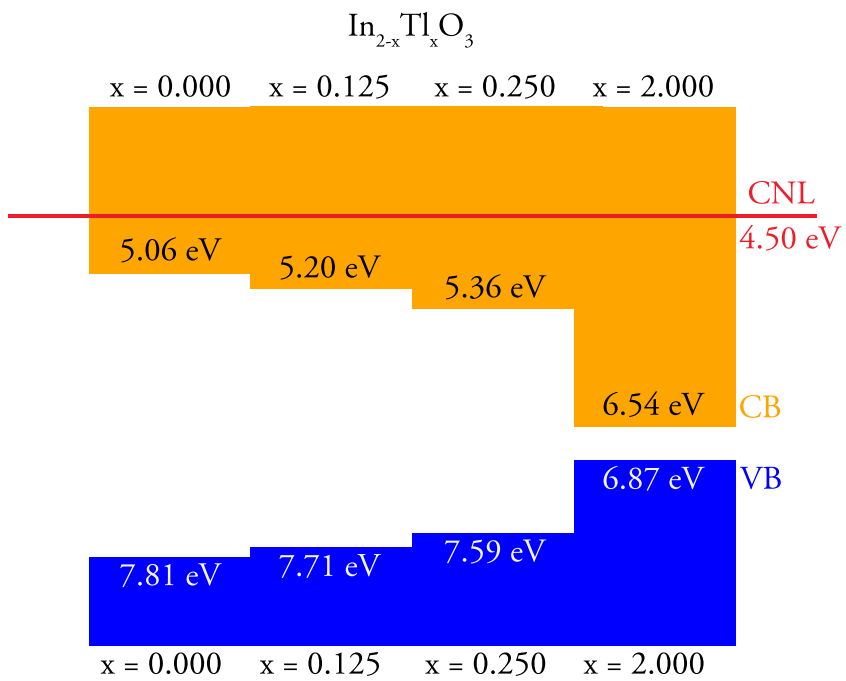

FIG. 3. Band alignment of $\operatorname{In}_{2-x} \mathrm{Tl}_{\mathrm{x}} \mathrm{O}_{3}$ for $\mathrm{x}=0.000,0.125,0.250$, and 2.000 calculated using the CNL alignment method. All energies are given relative to the vacuum level, using the assumption that the CNL sits at $\sim 4.5 \mathrm{eV}$ below the vacuum level. ${ }^{20}$

an electron accumulation layer. ${ }^{7}$ Despite these complications changes in the position of the valence band edge upon alloying with $\mathrm{Tl}$ can be regarded as significant. It is therefore interesting to find that the valence band edge moves to lower binding energy with incorporation of $\mathrm{Tl}$, with an onset at $2.49 \mathrm{eV}$ for a surface $\mathrm{x}$ value 0.36 . Since binding energies are referenced relative to the Fermi energy, which lies close to the CBM, this indicates narrowing of the bandgap in the

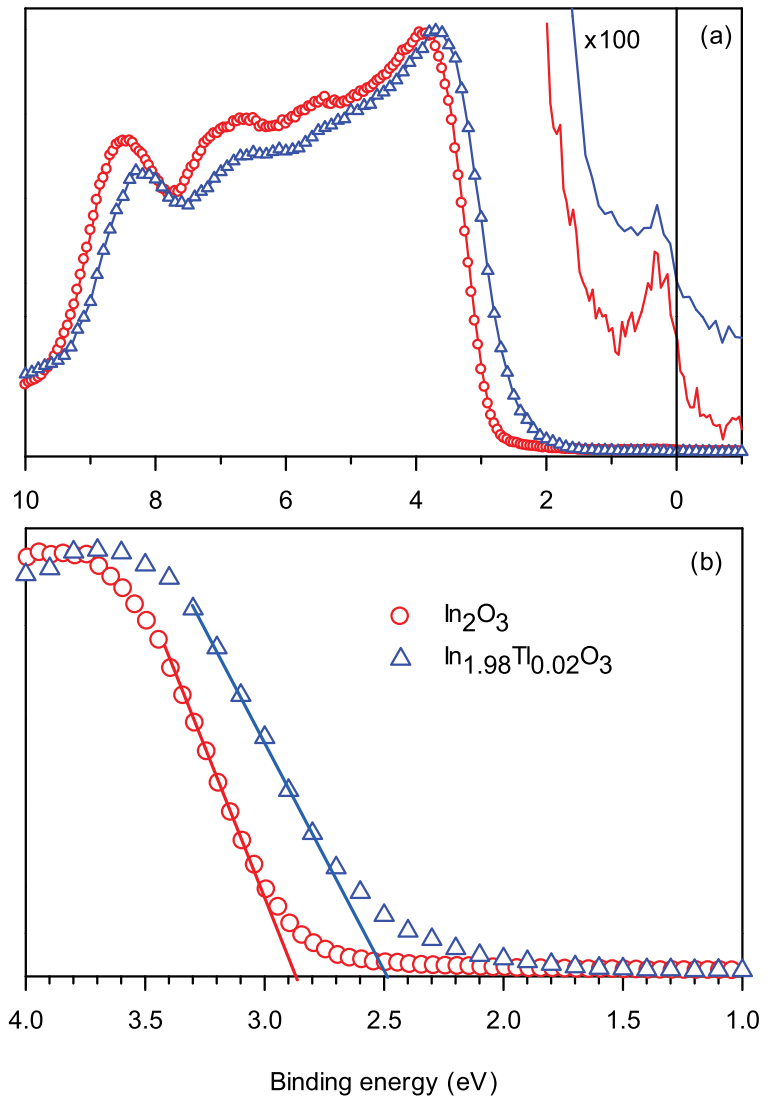

FIG. 4. (a) Valence band photoemission spectra of undoped $\operatorname{In}_{2} \mathrm{O}_{3}$ and a samples with nominal bulk composition $\mathrm{In}_{1.98} \mathrm{Tl}_{0.02} \mathrm{O}_{3}$. (b) Expanded views of the low binding energy region showing the linear extrapolation procedure used to define the position of the valence band edge. 
surface region probed by XPS assuming that there is no change in the band bending. Somewhat surprisingly however the intensity of the emission from conduction band states close to the Fermi energy decreases slightly with increasing Tl doping. In fact for a sample with nominal bulk composition $\mathrm{In}_{1.88} \mathrm{Tl}_{0.12} \mathrm{O}_{3}$ it was not possible to locate the Fermi edge with any confidence. Coupled with the very pronounced surface segregation of $\mathrm{Tl}$ found for both samples, these observations suggest that $\mathrm{Tl}$ may be partly accommodated at the surface as $\mathrm{Tl}^{+}$: the propensity of lone pair cations of this sort to segregate to surface sites is well documented. ${ }^{26,27}$ The $\mathrm{Tl}^{+}$would effectively act a two electron acceptor, partly compensating the charge carriers arising from oxygen vacancies or other native donor defects. Compensation of this sort has been found in Bi-doped $\mathrm{PbO}_{2}$, where $\mathrm{Bi}$ acts as an acceptor rather than as a donor. In the formally related system $\mathrm{Sb}$-doped $\mathrm{SnO}_{2}$ the $\mathrm{Sb}$ acts as a donor, as expected from simple electron counting considerations. ${ }^{27,28}$ Support for the idea of accommodation of a fraction of the $\mathrm{Tl}$ in surface sites as $\mathrm{Tl}^{+}$is provided by the observation that the intensity of photoemission in the bandgap region immediately above the extrapolated valence band edge is stronger in the alloy samples than in undoped $\mathrm{In}_{2} \mathrm{O}_{3}$ : this is where the antibonding lone pair states are expected.

Overall then it must be acknowledged that even though XPS provides tantalising evidence of bandgap narrowing in $\mathrm{In}_{2-\mathrm{x}} \mathrm{Tl}_{\mathrm{x}} \mathrm{O}_{3}$, the experimental work does highlight obvious difficulty in incorporating $\mathrm{Tl}$ in the bulk of $\mathrm{In}_{2} \mathrm{O}_{3}$ and also suggests that $\mathrm{Tl}$ may act to compensate native donors when it segregates to the surface. However the results are sufficiently encouraging to warrant investigation of deposition of $\mathrm{In}_{2-\mathrm{x}} \mathrm{Tl}_{\mathrm{x}} \mathrm{O}_{3}$ thin films although several safety issues need to be resolved before we can embark on this work.

Hybrid DFT calculations combined with high resolution XPS measurements have demonstrated that $\mathrm{Tl}$ incorporation into $\mathrm{In}_{2} \mathrm{O}_{3}$ can lead to a significant reduction in the band gap, arising from pronounced stabilisation of the CBM relative to the vacuum level. Concomitant lowering of the effective mass at the conduction band edge is predicted by the calculations, whilst maintaining optical transparency in the visible region. This effect should in principle make $\mathrm{In}_{2} \mathrm{O}_{3}: \mathrm{Tl}$ a more efficient $n$-type TCO even than $\operatorname{In}_{2} \mathrm{O}_{3}$. At the same time lowering of the CBM relative to the vacuum level will lead to an increase in the work function provided the Fermi level stays close to the CBM, as is found experimentally in the present work. This could lead to improved hole injection in organic light emitting diodes. These issues all warrant further experimental investigation, although difficulty in incorporating $\mathrm{Tl}$ into the bulk of $\operatorname{In}_{2} \mathrm{O}_{3}$ may well prove to be problematic.

The work presented here made use of the UCL Legion HPC Facility, the IRIDIS cluster provided by the EPSRC funded Centre for Innovation (EP/K000144/1 and EP/K000136/1), and the HECToR supercomputer through membership of the UK's HPC Materials Chemistry Consortium, which is funded by EPSRC grant (EP/F067496). The work in Dublin was supported by SFI through the PI programme (PI Grant Nos. 06/IN.1/I92 and 06/IN.1/I92/EC07) and made use of the Kelvin supercomputer as maintained by TCHPC. X-ray photoelectron spectroscopy was provided through the EPSRC "Access to Research Equipment Initiative: Cardiff XPS" (Grant No. EP/F019823/1).

${ }^{1}$ P. D. C. King and T. D. Veal, J. Phys.: Condens. Matter 23, 334214 (2011). ${ }^{2}$ B. J. Ingram, G. B. Gonzalez, D. R. Kammler, M. I. Bertoni, and T. O. Mason, J. Electroceram. 13, 167 (2004).

${ }^{3}$ A. Walsh, A. B. Kehoe, D. J. Temple, G. W. Watson, and D. O. Scanlon, Chem. Commun. 49, 448 (2013).

${ }^{4}$ X. Luo, Y. S. Oh, A. Sirenko, P. Gao, T. A. Tyson, K. Char, and S. W. Cheong, Appl. Phys. Lett. 100, 172112 (2012); H. J. Kim, U. Kim, T. H. Kim, J. Kim, H. M. Kim, B. G. Jeon, W. J. Lee, H. S. Mun, K. T. Hong, J. Yu, K. Char, and K. H. Kim, Phys. Rev. B 86, 165205 (2012); H. J. Kim, U. Kim, H. M. Kim, T. H. Kim, H. S. Mun, B. G. Jeon, K. T. Hong, W. J. Lee, C. Ju, K. H. Kim, and K. Char, Appl. Phys. Express 5, 061102 (2012); D. O. Scanlon, Phys. Rev. B 87, 161201(R) (2013); D. O. Scanlon and G. W. Watson, J. Mater. Chem. 22, 25236 (2012).

${ }^{5}$ A. Walsh, J. Buckeridge, C. R. A. Catlow, A. J. Jackson, T. W. Keal, M. Miskufova, P. Sherwood, S. A. Shevlin, M. B. Watkins, S. M. Woodley, and A. A. Sokol, Chem. Mater. 25, 2924 (2013); S. B. Zhang, J. Phys.: Condens. Matter 14, R881 (2002).

${ }^{6}$ A. Walsh, J. L. F. Da Silva, S. H. Wei, C. Korber, A. Klein, L. F. J. Piper, A. DeMasi, K. E. Smith, G. Panaccione, P. Torelli, D. J. Payne, A. Bourlange, and R. G. Egdell, Phys. Rev. Lett. 100, 167402 (2008).

${ }^{7}$ P. D. C. King, T. D. Veal, D. J. Payne, A. Bourlange, R. G. Egdell, and C. F. McConville, Phys. Rev. Lett. 101, 116808 (2008).

${ }^{8}$ K. H. L. Zhang, V. K. Lazarov, T. D. Veal, F. E. Oropeza, C. F. McConville, R. G. Egdell, and A. Walsh, J. Phys.: Condens. Matter 23, 334211 (2011); A. Walsh, C. R. A. Catlow, K. H. L. Zhang, and R. G. Egdell, Phys. Rev. B 83, 161202 (2011).

${ }^{9}$ D. O. Scanlon and A. Walsh, Appl. Phys. Lett. 100, 251911 (2012); N. Feldberg, J. D. Aldous, W. M. Linhart, L. J. Phillips, K. Durose, P. A. Stampe, R. J. Kennedy, D. O. Scanlon, G. Vardar III, R. L. Field, T. Y. Jen, R. S. Goldman, T. D. Veal, and S. M. Durbin, ibid. 103, 042109 (2013).

${ }^{10}$ M. H. Harunsani, F. E. Oropeza, R. G. Palgrave, and R. G. Egdell, Chem. Mater. 22, 1551 (2010).

${ }^{11}$ G. Kresse and J. Hafner, Phys. Rev. B 49, 14251 (1994).

${ }^{12}$ G. Kresse and D. Joubert, Phys. Rev. B 59, 1758 (1999).

${ }^{13}$ A. V. Krukau, O. A. Vydrov, A. F. Izmaylov, and G. E. Scuseria, J. Chem. Phys. 125, 224106 (2006).

${ }^{14}$ M. Burbano, D. O. Scanlon, and G. W. Watson, J. Am. Chem. Soc. 133, 15065 (2011); D. O. Scanlon, A. B. Kehoe, G. W. Watson, M. O. Jones, W. I. F. David, D. J. Payne, R. G. Egdell, P. P. Edwards, and A. Walsh, Phys. Rev. Lett. 107, 246402 (2011); J. P. Allen, D. O. Scanlon, and G. W. Watson, Phys. Rev. B 81, 161103(R) (2010); D. O. Scanlon and G. W. Watson, J. Mater. Chem. 21, 3655 (2011).

${ }^{15}$ A. B. Kehoe, D. O. Scanlon, and G. W. Watson, Phys. Rev. B 83, 233202 (2011).

${ }^{16}$ P. Agoston, K. Albe, R. M. Nieminen, and M. J. Puska, Phys. Rev. Lett. 103, 245501 (2009).

${ }^{17}$ M. Gajdos, K. Hummer, G. Kresse, J. Furthmuller, and F. Bechstedt, Phys. Rev. B 73, 045112 (2006).

${ }^{18}$ B. Adolph, J. Furthmuller, and F. Bechstedt, Phys. Rev. B 63, 125108 (2001).

${ }^{19}$ P. A. Glans, T. Learmonth, K. E. Smith, J. Guo, A. Walsh, G. W. Watson, F. Terzi, and R. G. Egdell, Phys. Rev. B 71, 235109 (2005).

${ }^{20}$ A. Schleife, F. Fuchs, C. Rodl, J. Furthmuller, and F. Bechstedt, Appl. Phys. Lett. 94, 012104 (2009).

${ }^{21}$ A. Walsh and C. R. A. Catlow, J. Mater. Chem. 20, 10438 (2010).

${ }^{22}$ M. V. Hohmann, P. Agoston, A. Wachau, T. J. M. Bayer, J. Brotz, K. Albe, and A. Klein, J. Phys.: Condens. Matter 23, 334203 (2011).

${ }^{23}$ S. Lany and A. Zunger, Phys. Rev. Lett. 106, 069601 (2011).

${ }^{24}$ A. Bourlange, D. J. Payne, R. G. Egdell, J. S. Foord, P. P. Edwards, M. O. Jones, A. Schertel, P. J. Dobson, and J. L. Hutchison, Appl. Phys. Lett. 92, 092117 (2008).

${ }^{25}$ P. D. C. King, T. D. Veal, F. Fuchs, C. Y. Wang, D. J. Payne, A. Bourlange, H. L. Zhang, G. R. Bell, V. Cimalla, O. Ambacher, R. G. Egdell, F. Bechstedt, and C. F. McConville, Phys. Rev. B 79, 205211 (2009).

${ }^{26}$ P. A. Cox, R. G. Egdell, C. Harding, W. R. Patterson, and P. J. Tavener, Surf. Sci. 123, 179 (1982); A. Gulino, A. F. Tavener, S. Warren, P. Harris, and R. G. Egdell, Surf. Sci. 315, 351 (1994).

${ }^{27}$ S. Rothenberg, D. J. Payne, A. Bourlange, and R. G. Egdell, J. Appl. Phys. 102, 113717 (2007).

${ }^{28}$ P. A. Cox, R. G. Egdell, C. Harding, A. F. Orchard, and W. R. Patterson, Solid State Commun. 44, 837 (1982). 